\title{
Treatment and Follow-up for Teeth with Apical Lesion after Complicated Crown Fracture
}

\author{
Bilge 0zcan*1 and Bade Sonat ${ }^{2}$ \\ ${ }^{1}$ Turkish Ministry of Health Mamak Oral and Dental Health Center, Turkey \\ ${ }^{2}$ Ankara University, Faculty of Dentistry, Department of Endodontics, Turkey \\ *Corresponding author: Bilge Ozcan, Turkish Ministry of Health Mamak Oral, Dental Health Center, Ankara, Turkey
}

\section{ARTICLE INFO}

Received: 菲 May 21, 2021

Published: 幽 June 15, 2021

Citation: Bilge Ozcan, Bade Sonat. Treatment and Follow-up for Teeth with Apical Lesion after Complicated Crown Fracture. Biomed J Sci \& Tech Res 36(3)-2021. BJSTR. MS.ID.005865.

Keywords: Dental Trauma; Complicated Crown Fracture; $\mathrm{CaOH}$ Medication

\begin{abstract}
One of the reasons for emergency admission in dentistry is dental trauma. Crown fractures in anterior teeth are the most common form of dental trauma, and maxillary incisors are the most frequently affected teeth due to their position in the arch. Crown fractures of permanent incisors are seen in $18-22 \%$ of traumas in dental hard tissues, these are $28-44 \%$ simple (enamel and dentin) and $11-15 \%$ complicated (enamel, dentin and pulp) crown fractures. It was learned that a 17 -year-old female patient who applied to the clinic with pain complaints had broken upper anterior teeth due to an accident 8 months ago. It was observed that a fistula developed in the periapical of tooth number 11. Tooth number 11 was diagnosed with chronic apical abscess and tooth number 21 was diagnosed as chronic apical periodontitis. Multi-session root canal treatment was applied with $\mathrm{CaOH}$ medication and root canals were filled with cold lateral compaction method. The patient was followed up. In the control radiography taken 1 year later, periapical lesions healed, and no periapical surgery was required. When planning the treatment, the type of fracture, the age of the patient, the time passed after the trauma, and the condition of the periapical and pulpal tissues should be evaluated. Before the endodontic treatment of cases with large periapical lesions is completed, dressing by applying $\mathrm{Ca}(\mathrm{OH}) 2$ for a certain period of time is a factor that positively affects the success.
\end{abstract}

\section{Introduction}

One of the reasons for emergency admission in dentistry is dental trauma. Dental trauma can be seen at any age. These injuries to the teeth range from simple enamel cracks to complicated fractures and often require complex treatment of more than one injury type. Crown fractures in anterior teeth are the most common form of dental trauma, and maxillary incisors are the most frequently affected teeth due to their position in the arch [1]. Crown fractures of permanent incisors are seen in $18-22 \%$ of traumas in dental hard tissues, these are $28-44 \%$ simple (enamel and dentin) and $11-15 \%$ complicated (enamel, dentin, and pulp) crown fractures [2]. In determining treatment options for crown fractures; The location of the fracture, the size of the fracture fragments, the condition of the periodontal tissue and pulp, the development of the root, occlusion, aesthetics and the time after the trauma are evaluated. The treatment method to be chosen in such fractures usually depends on the duration of the pulp tissue open and the size of the perforation [3]. The patient's application time to the health center is important in terms of the course of the treatment. Pulp capping and pulpotomies are the primary treatment options. Timely preventive treatments prevent the development of pulp and periapical tissue diseases. Chronic apical abscess is a pulp-borne inflammatory lesion characterized by the presence of long-lasting lesions that result in resistance to the mucosa or skin surface, causing an abscess. It can remain in the apical area for a long time without any clinical symptoms. However, in the presence of a fistula, the occasional opening of the fistula and flowing into the mouth can be noticed by the patient. Its etiology stems from pulp necrosis and is generally associated with chronic apical periodontitis with 
abscess formation [4]. The aim of this case report is to explain the treatment and follow-up of teeth with chronic apical abscess that develops in upper central teeth that have been traumatized but could not be intervened early.

\section{Case Report}

It was learned that a 17-year-old female patient, who applied to Ankara University Faculty of Dentistry Endodontics clinic with a complaint of pain, had a fracture in her upper anterior teeth as a result of an accident 8 months ago. In the clinical evaluation of the patient, who did not find any disease in his clinical history, it was observed that there were crown fractures in teeth number 11 and 21, and fistula developed in the periapical of tooth number 11 (Figure 1). On radiographic examination, presence of periapical lesions was observed at the root tip of teeth numbered 11 and 21 (Figures $2 \& 3$ ) Tooth number 11 was diagnosed with chronic apical abscess and tooth number 21 was diagnosed as chronic apical periodontitis. First, the access cavity was opened, and the root canal length was determined radiographically using \# 20 and \# 25
$\mathrm{K}$ files. Since the teeth were devital in the first session, they were not prepared too much, and cotton pellets containing disinfectant (Cresephone; Septodont, France) were placed in the cavity because of the pus drainage, and the teeth were temporarily restored using temporary filling material (Cavit G, 3M ESPE, Germany) (Figure 4). After 2 days, the teeth were reopened and their apices were prepared using a step-back technique up to a \# $40 \mathrm{~K}$ file. In each session, root canals were irrigated with 5.25\% NaOCl (Wizard, Rehber Kimya, Istanbul, Turkey). In the second session, Ca (OH) 2 medication was placed inside the canal, as no pus flow was observed in the channels. Root canal dressing was applied to the patient two times with an interval of two weeks (Figure 5). In the last session, the root canals were irrigated with saline and dried with sterile paper cones and the AH Plus (Dentsply DeTrey, Konstanz, Germany) duct sealer was suitable for cold lateral compaction technique. The teeth were directly restored with composite filling material in the same session. In the control radiography taken one year later, it was found that periapical radiolucent lesions observed at the root tips healed and replaced with healthy bone tissue (Figure 6).

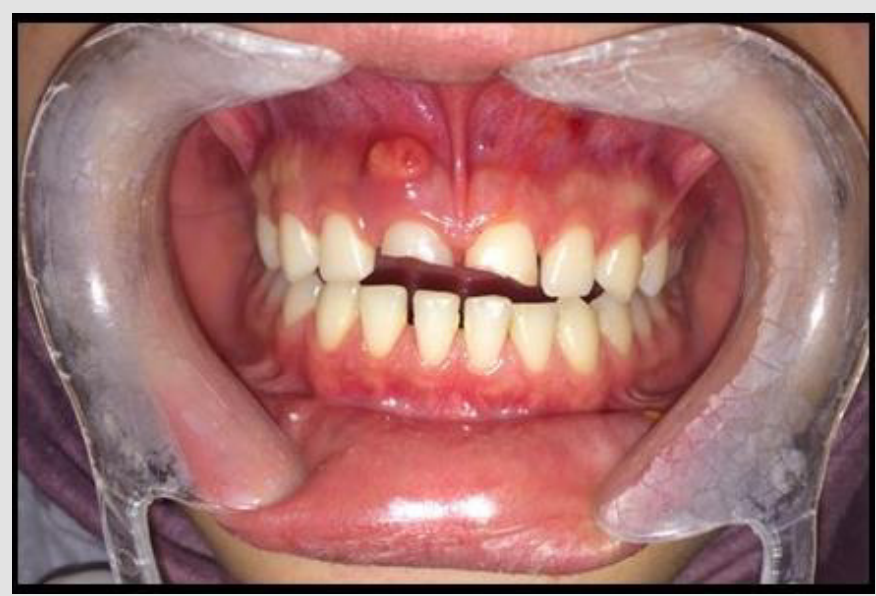

Figure 1: Fistula view on tooth number 11(left),

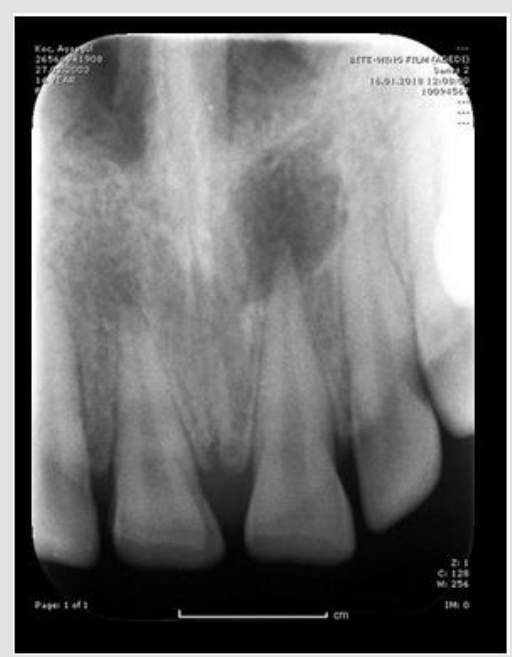

Figure 2: Periapical radiography of teeth 11 and 21, monitoring radiolucent lesion areas (right). 


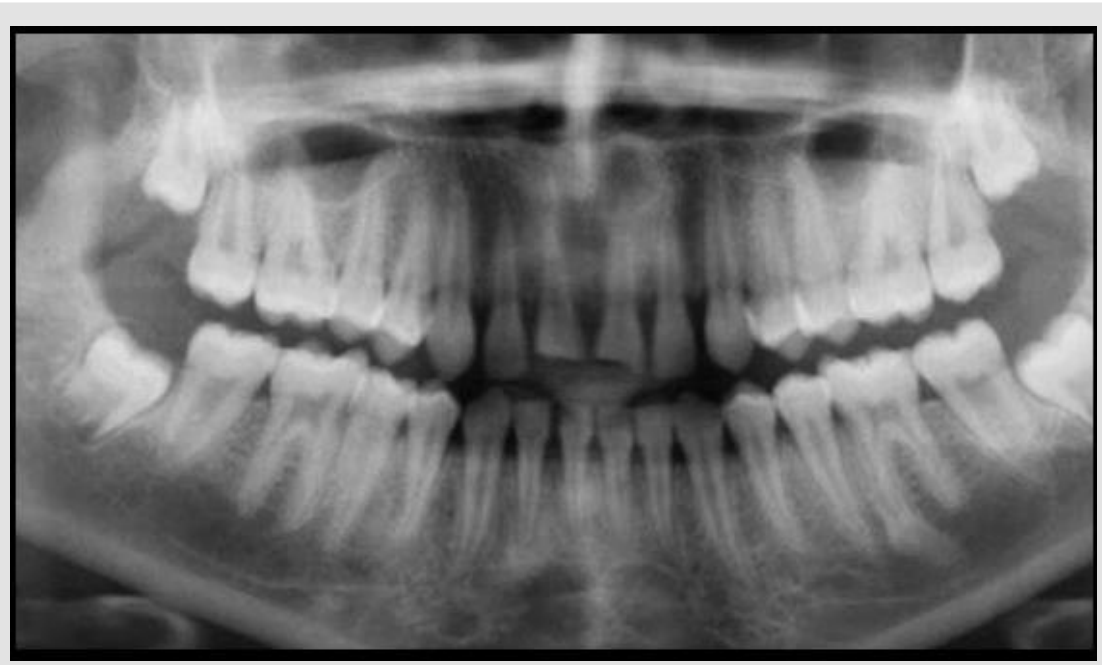

Figure 3: Panoramic radiographic view.

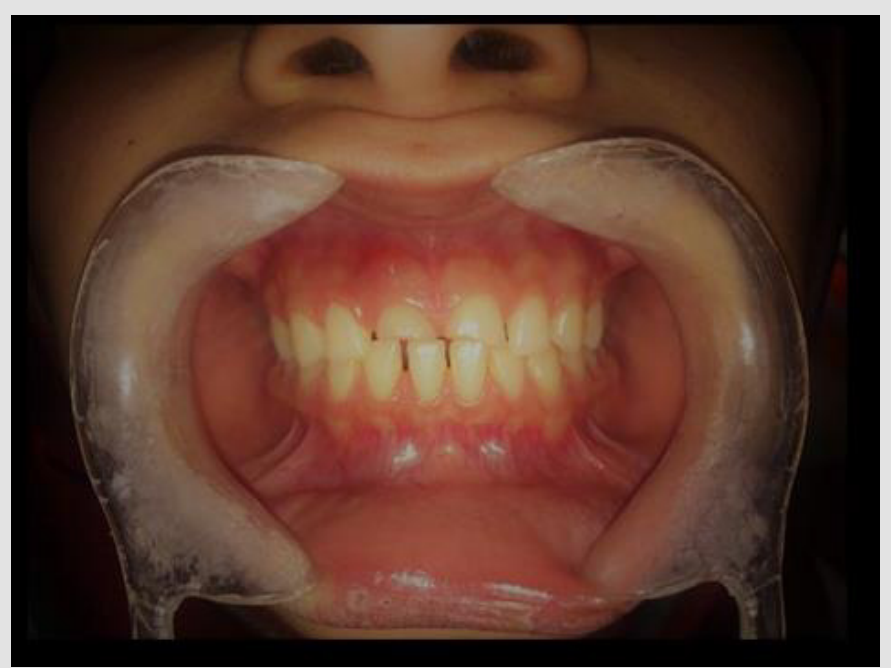

Figure 4: Intraoral view of the closed fistula after $\mathrm{CaOH}$ medication applied between sessions.

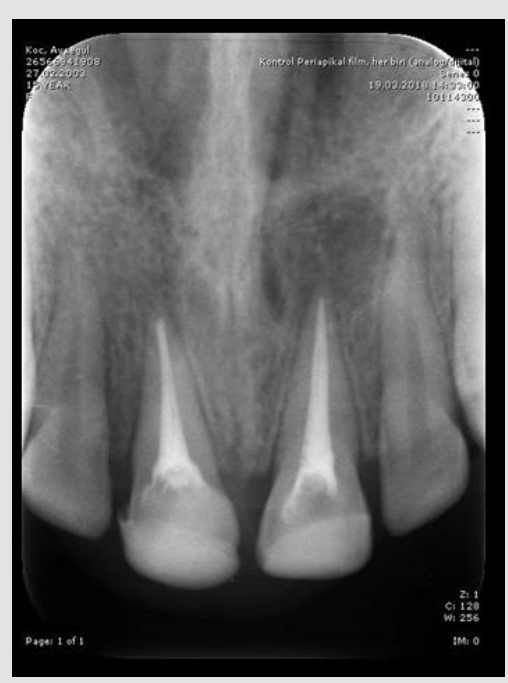

Figure 5: Root canal filling was completed in the final session. 


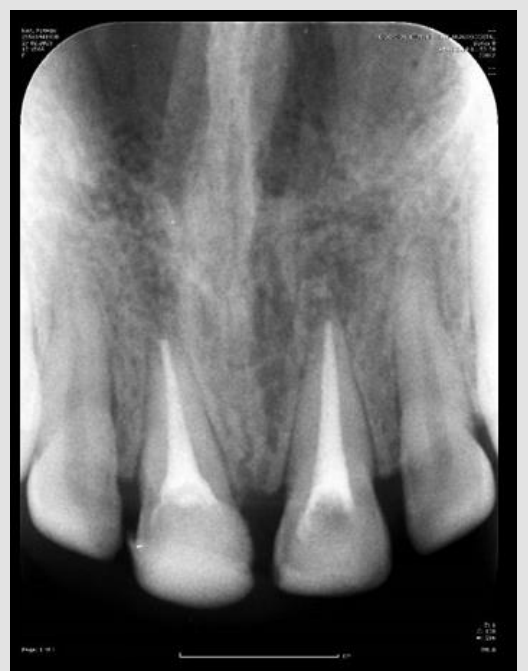

Figure 6: Control radiography taken 1 year later.

\section{Results}

During the 1-year follow-up period, it was found that the affected teeth were asymptomatic in clinical evaluations, the existing fistula was closed, there was no percussion sensitivity, and the radiolucent lesion present in the radiography had healed. The treatment of the teeth was completed with only endodontic treatment without the need for any surgical procedure. No deformation was found in the composite restoration.

\section{Discussion}

As a result of a literature review, it was revealed that $25 \%$ of all school-term children had a dental injury, and $33 \%$ of adults were exposed to permanent trauma in their teeth, mostly before the age of 19 [5]. When planning the treatment, the type of fracture, the age of the patient, the time passed after the trauma, and the condition of the periapical and pulpal tissues should be evaluated. Depending on the size of the pulp opening, direct hairdressing or root canal treatment can be performed in complicated crown fractures [6,7]. Root canal treatment was applied in this patient, considering the time elapsed after the trauma and the condition of the periapical tissues. Before the endodontic treatment of cases with large periapical lesions is completed, dressing by applying Ca $(\mathrm{OH}) 2$ for a certain period is a factor that positively affects the success [8]. Since apical periodontitis and cysts have very similar images radiographically, histopathological tests should be used in the correct diagnosis besides radiography. There is a strong difference of opinion regarding the treatment of large periapical lesions with surgical methods such as traditional root canal treatment or apical resection, but many studies reported that apical lesions up to 20 mm improved with traditional root canal treatment $[9,10]$. Apart from the correct and complete endodontic treatment, the only factor in the healing of periapical lesions is personal wound healing factors [11]. Considering the age of this patient and the absence of systemic disease, it was thought that root canal therapy would be sufficient in healing apical lesions, and only multi-session root canal treatment was applied to the patient and the patient was followed up. Control radiography was taken 1 year after the patient and it was observed that the radiolucent lesion areas observed in the periapical tissue were replaced by healthy bone tissue.

\section{References}

1. Dietschi D, Jacoby T, Dietschi JM, Schatz JP (2000) Treatment of traumatic injuries in the front teeth: Restorative aspects in crown fractures. Pract Periodontics Aesthet Dent 12(8): 751-8.

2. Divakar HD, Nayak M, Shetty R (2007) Changing concepts in fracture reattachment of teeth-a case series. Endod 2013: 27-35.

3. Andreasen JO, Andreasen FM (1994) Classification, etiology and epidemiology Textbook and Color Atlas of Traumatic Injuries to the Teeth. Copenhagen: Munksgard s, pp. 151-80.

4. Bhaskar SN (1966) Periapical lesion: types, incidence, and clinical features. Oral Surg Oral Med Oral Pathol 21(5): 657-671.

5. Glendor U (2008) Epidemiology of traumatic dental injuries- a 12 year review of the literatüre. Dent Traumatol 24: 603-11.

6. Burke FJ (1991) Reattachment of a fractured central incisor tooth fragment. Br Dent J 170(6): 223-5.

7. Tulunoğlu F, Görduysus Ö (1997) A simple method for the restoration of fractured anterior teeth. J Prosthet Dent 78(6): 614-5.

8. Paredes Vieyra J, Enriquez FJ (2012) Success Rate of Single-versus Two-visit Root Canal Treatment of Teeth with Apical Periodontitis: A Randomized Controlled Trial. J Endod 38(9): 1164-9.

9. Mirković S, Tadić A, Durdević Mirković T, Levakov A (2012) Comparative analysis of accuracy of diagnosis of chronic periapical lesions made by clinical and histopatological examination. Med Pregl 65(7-8): 277-280.

10. Riccitiello F, Stabile P, Amato M, Rengo S, D’Ambrosio C (2011) The treatment of the large periradicular endodontic injury. Minerva Stomatol 60(9): 417-26.

11. Garlet GP, Horwat R, Ray HL Jr, Garlet TP, Silveira EM, et al. (2012) Expression analysis of wound healing genes in human periapical granulomas of progressive and stable nature. J Endod 38(2): 85-90. 
ISSN: 2574-1241

DOI: 10.26717/BJSTR.2021.36.005865

Bilge Ozcan. Biomed J Sci \& Tech Res

(c) (P) This work is licensed under Creative

Submission Link: https://biomedres.us/submit-manuscript.php

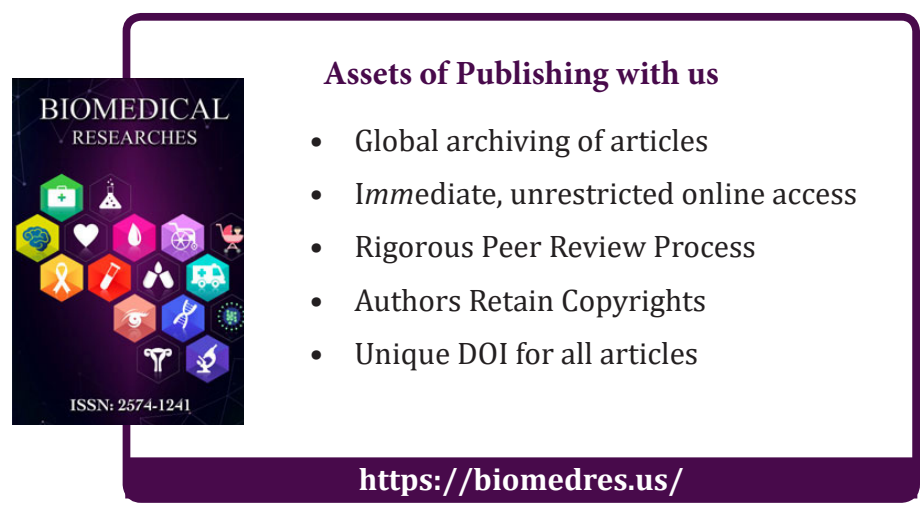

